\title{
Religión y Sentido de Justicia Social. La Corporación de Estudiantes Mexicanos
}

\section{Religion and sense of Social Justice. The Mexican Students Corporation Religião e Sentido de Justiça Social. A Corporação de Estudantes Mexicanos}

\section{Resumen}

Los grupos católicos en México han sido reconocidos como conservadores en la medida en que han desarrollado intenso trabajo en la defensa de los valores religiosos. Esta fue la forma fundamental que les sostuvo activos en las primeras décadas del siglo XX. Sin embargo, la Corporación de Estudiantes Mexicanos, fundada en 1947, implicó una organización muy importante para algunos de los jóvenes que se integraron a ella, fundamentalmente de la Universidad Nacional, por las actividades que desarrollaban. Como podemos ver, hay una transición que corre a la par con
Gabriela Contreras Pérez gacosp@gmail.com Recibido: 6 de junio 2016 Aprobado: 3 de octubre 2016

los cambios sociales ocurridos en los años signados por la Guerra Fría y por las luchas por los derechos civiles. Ello significó un cambio en las actividades de la Corporación de Estudiantes Mexicanos, a principios de los años sesenta, realizando actividades más sociales, cívicas y políticas. Este trabajo explora el contexto histórico y las condiciones que hicieron posible la emergencia de otras expresiones, no de la organización en sí, sino expresiones paralelas. Se observa una transición que va de la caridad hacia el reclamo de justicia social que promovió movimientos sociales. 


\section{SIWÔ ${ }_{\text {Volumen 9, Numeres } 1,2015}$}

Palabras Clave: religión, justicia social, Corporación de Estudiantes Mexicanos

\begin{abstract}
Catholic students groups in México have been recognized as conservatives because of their intensive work as activists for the defence of religious values. This is the main way they were active during the first decades of the twentieth century. Nevertheless, the Mexican Students Corporation founded in 1947 made a distinction for some of these young people, mainly from the Universidad $\mathrm{Na}$ cional because of the activities they made. As we can see, there is a transition that runs alongside the changes on society during those years signed by the cold war and the important fights for civil rights. This implied a change on the Mexican Students Corporation during the early sixties, who were developing more social, civic and political activities. This work explores the historical context and conditions that made the emergence of other expressions possible not from the organization itself but parallel to it. A transition is observed which goes from charity to the claim of social justice that promoted social empowerment.
\end{abstract}

Keywords: Religion, social justice, The Mexican Students Corporation

\section{Resumo}

Os grupos católicos no México têm sido reconhecidos como conservadores na medida em que desenvolvem intenso trabalho na defesa dos valores religiosos. Esta foi a forma fundamental que os manteve ativos nas primeiras décadas do século XX. No entanto, a Corporação de Estudantes Mexicanos, fundada em 1947, significou uma organização muito importante para alguns dos jovens que se integraram a ela, fundamentalmente da Universidade Nacional, pelas atividades que desenvolviam. Como podemos ver, há uma transição que acontece junto com as mudanças sociais ocorridas nos anos marcados pela Guerra Fria e pelas lutas pelos direitos civis. Isto significou uma mudança nas atividades da Corporação de Estudantes Mexicanos, a princípio dos anos sessenta, realizando atividades mais sociais, cívicas e políticas. Este trabalho explora o contexto histórico e as condições que fizeram possível a emergência de outras expressões, não da organização em si, mas expressões paralelas. Observa-se uma transição que vai da caridade para a reivindicação de justiça social que promoveu movimentos sociais.

Palavras Chave: Religião, justiça social, Corporação de Estudantes Mexicanos 
Los años cuarenta, en México, estuvieron marcados por un ambicioso proyecto de transformación social y económica. Los elementos culturales que marcaron a los años de la Guerra Fría van más allá de la dicotomía entre el bloque socialista y el mundo capitalista. Los jóvenes nacidos al término de la Segunda Guerra Mundial, crecieron en un mundo caracterizado por esas dualidades, ese conflicto entre mundos, ruptura de valores, gestación de nuevas normas sociales, un mundo bipolar que resultaba poco esperanzador. Ante esas circunstancias, el papel de la Iglesia resultó relevante para muchas familias, sobre todo porque constituía un refugio, un punto de referencia que posibilitaba la reconstrucción social, que proporcionaba ayuda a los desamparados y que pretendía fortalecer los valores de esperanza y caridad mediante la fe.

No obstante, las mismas circunstancias que habían propiciado una especie de recogimiento social, esto es la guerra, generó cambios sociales importantes a lo largo de las décadas de los cincuenta y sesenta. Cambios en donde los jóvenes tuvieron un papel fundamental en la lucha por el reconocimiento de los derechos de los negros, en su rechazo a continuar sirviendo carne de cañón en las guerras invasoras, en la lucha por ser reconocidos como ciudadanos, en las luchas, al fin, por el reconocimiento de los derechos de la mujer.

Así, si en esos años cincuenta habíamos encontrado a los jóvenes actuando desde la caridad para aminorar los efectos de la marginación, la exclusión y la pobreza, a mediados de los años sesenta y a lo largo de la década siguiente, los encontraremos luchando y actuando por la justicia social.

En este trabajo se hace una breve exposición de este proceso, a la luz de la Corporación de Estudiantes Mexicanos. 
1. En el año de 1947 se ubica la fundación de una de las organizaciones católicas orientada hacia la población estudiantil que habría de tener una importante trayectoria y gran influencia en diversas instituciones de educación superior en México: se trata de la Corporación de Estudiantes Mexicanos (CEM), frente a la cual estuvo como Asesor Eclesiástico Nacional el sacerdote Jesuita David Mayagoitia S. J., un poco más de 20 años ${ }^{1}$.

Las actividades de hombres y mujeres estaban divididas en sectores, por lo que los varones estaban en la Corporación. Las mujeres estaban aglutinadas en la Unión Femenina de Estudiantes Católicas (UFEC), pero a la vez integradas, desde esta frontera organizativa, a la misma CEM. En muy poco tiempo consiguieron tener pequeños grupos con una estructura muy definida y con el respaldo de la Jerarquía Católica tuvieron presencia en distintas escuelas a lo largo del país, con el principio "Por Cristo en la Universidad", orientando sus discusiones en los círculos de estudio, lecturas y actividades diversas como ejercicios espirituales, retiros o ejercicios de encierro. Cada grupo tenía sus seccionales por escuela y luego, por entidad, atendiendo a reuniones y actividades específicas dentro de sus instituciones educativas, de manera abierta, sin secretismos, procurando ganar posiciones entre los estudiantes, así como en las representaciones ante los Consejos. Como parte de sus tareas de proselitismo promovían conferencias con temas de actualidad mismos que podían abonar a la reflexión interna de los grupos, sobre Ciencia y Fe. Una constante era, por ejemplo, la preocupación por la influencia de la masonería o el comunismo en el medio universitario frente a la cual la población de jóvenes de la Corporación y de UFEC debían tener siempre presente "el llamamiento de Cristo, para que

1 En relación con los orígenes de la Corporación de Estudiantes Mexicanos, véase Contreras, Gabriela, Los grupos católicos en la Universidad Autónoma de México, México, Universidad Autónoma Metropolitana, Colección Breviarios, 2002. 
contribuyan, de la manera más perfecta posible, a la realización de la caridad y la justicia social..."

La reflexión e informe proporcionados cada reunión anual era base para la planeación del siguiente año. Anualmente se reunían en las asambleas nacionales al igual que en las llamadas semanas de estudios, eventos presididos por el padre David Mayagoitia, en donde discutían diversos tópicos. Una característica fundamental de la Corporación era que -desde su origen- estaba desvinculada de la línea definida por Acción Católica Mexicana ${ }^{3}$, lo cual le imprimió un cierto carácter novedoso en su práctica que ante algunos de sus críticos podía implicar cierta cercanía y relativa similitud con grupos católicos de años anteriores que eran supuestamente independientes de la jerarquía católica ${ }^{4}$ : la CEM tenía como uno de sus propósitos influir en las discusiones académicas y de organización de las instituciones educativas en las que estaba. Era una forma, una mediación para incidir en grupos de la población que constituían al menos potencialmente: el grupo de educadores, de mandos medios, intelectuales y empresarios. Desde esta organización se quería influir en la formación espiritual, fortalecer las discusiones sobre razón y fe, subrayando la necesidad de tener profesionistas responsables que contribuyeran así a la sociedad. Además, estaban haciendo uso

2 Archivo David Mayagoitia (en adelante ADM) Universidad Iberoamericana, Corporación de Estudiantes Mexicanos, XIV Asamblea Nacional y X Semana de Estudios. Plan Nacional de Trabajo, 26 - 30 de diciembre, 1962, Cuernavaca, Morelos.

3 Véase Aspe Armella, Ma. Luisa. La formación social y política de los mexicanos, México, Departamento de Historia/ Universidad Iberoamericana/ Instituto Mexicanos de Doctrina Social Cristiana, 2008. Si bien hacia fines de los años cincuenta la fuerza de Acción Católica iba disminuyendo, debe considerarse que hay variaciones locales que definieron la "organización y dirección del apostolado laico" de modo diverso, es decir, la presencia y fuerza local de esta organización dependía de las condiciones locales. El surgimiento de nuevos grupos como el Movimiento de Estudiantes y Profesionales, se enmarca en este contexto.

4 Véase Contreras, G., op cit. 
de un espacio (el universitario), que poco a poco se definía como medio para el ascenso social.

La Revista Corporación servía también a estos propósitos, proponiendo sus particulares puntos de vista sobre temas de carácter histórico, las diversas actividades de grupos similares en otros países, reflexiones sobre la juventud y su papel en la sociedad, algunas noticias sobre organizaciones de la socialdemocracia en Europa y propuestas sobre la necesidad de formar conciencia, sin olvidar la vocación social y responsabilidad que tenían como corporacionistas y como jóvenes estudiantes.

La lectura que a inicios de los años sesenta se estaba haciendo de la sociedad desde CEM y UFEC, era muy general: sin relación espacial ni temporal. Esto es, que no pretendían un cambio social a partir de sus postulados.

El planteamiento, aparte de corresponder a la cotidianidad urbana, considera las estructuras institucionales y analiza su funcionamiento en términos de lo que eran los propósitos de estas dos organizaciones. Su vinculación con los sectores estudiantiles marcará un parteaguas en su orientación, no porque se radicalicen sino por los efectos de cambio que se darán primero, en el plano de organización interna y, posteriormente en términos individuales, sobre todo a partir de su involucramiento en el movimiento estudiantil de 1968.

De la discusión sobre la pastoral pasarán al análisis de los acontecimientos en los que poco a poco se irán involucrando. Esto sucede a la par de la emergencia de propuestas de reflexión sobre su quehacer, en relación con el significado de la acción caritativa y, sobre todo, en relación con el sentido de la justicia social ¿Resultó éste un concepto reducido en relación con la realidad social? 
Propiciar estas discusiones tenía como fin aportar elementos de reflexión sobre la relación entre razón y fe; ciencia y religión, es decir, se trataba de reflexiones profundas que en no pocas ocasiones implicó la búsqueda de lecturas que no necesariamente estaban entre aquellas seleccionadas o aprobadas por la jerarquía católica.

2. Entre algunos grupos de jóvenes, por ejemplo, la lectura de los textos de Teilhard de Chardin ${ }^{5}$ resultó una reflexión innovadora e inquietante. Su planteamiento fundamental sobre el proceso de la evolución sugiere como es que el ser humano llegaba a tener consciencia de sí mismo, de su proceso de evolución. Este proceso implica que hay un origen y un sentido. Esta línea de pensamiento orienta hacia la reflexión de la actividad social, hacia la suma de esfuerzos más allá de la espiritualidad y reflexión individual. Una idea del quién soy y hacia dónde voy, ¿cuál es el sentido de mi ser? ¿Cuál es el sentido de nuestros actos y decisiones?

Chardin sugiere una explicación del origen del universo que, si bien contempla elementos teológicos, al hablar de consciencia está situando al ser humano al centro de su mundo, con un saber (científico), con capacidades de sentir, pensar y actuar para sí

5 Teilhard de Chardin, jesuita francés (1881-1955), dedicó varios años de su vida a los estudios de Geología, Botánica y Zoología, aunque es reconocido también por su interés en la Paleontología. Viajero incansable, sus primeras publicaciones, elaboradas cuando entraba a la tercera década de su vida, contenían ya elementos de lo que fue el núcleo de su pensamiento que llega a sugerir posiciones críticas de la doctrina católica. Sus libros fueron prohibidos el 6 de diciembre de 1957, por decreto del Santo Oficio: "Los libros del Padre Teilhard de Chardin deben ser retirados de las bibliotecas de los Seminarios e Instituciones religiosas; no pueden ser puestos a la venta en librerías católicas y no es lícito traducirlas a otras lenguas". En suma, se consideró que sus postulados eran "ambiguos" y propiciaba la confusión en los lectores jóvenes. No obstante, en los años cincuenta surgieron diversas críticas hacia su postura filosófica y teológica; en 1962 inicia un proceso de intensa discusión pues se pretendía evitar la reivindicación de su obra, punto que concluyó cuando este jesuita fue recuperado por el Papa Paulo VI, en 1966. 
mismo y para otros. Se transita hacia la ciencia de la historia, en donde "Dios, esa soberana realidad, deja de ser soberana"; donde la esencia del concepto de Dios "no sería Ser, sino Unir".

En todo caso, el análisis filosófico de la obra del Padre Chardin y sus implicaciones va más allá de este breve texto. Lo que interesa destacar es que hubo un fuerte impacto entre aquellos que le leyeron, que no fueron pocos, al menos en los grupos de la Ciudad de México. Aquí lo que interesa es tratar de comprender la manera en que las discusiones y la búsqueda de lecturas y nuevos autores, iba desencadenando nuevas posturas al interior de la CEM que, en el contexto que se iba gestando en los años sesenta, sería relevante para los cambios en la forma de actuar de la población joven.

De este punto de reflexión y considerando la compleja realidad socio económica en la que vivían, muchos jóvenes corporacionistas llegaron al planteamiento de la necesidad de justicia social y caridad. Las condiciones sociales y de movilización política que privaban en México cuando la Corporación celebró sus primeros diez años de vida, esto es, en 1958, impactó no solo las discusiones en el ámbito universitarias o en las escuelas particulares, sino en la misma vida cotidiana de los jóvenes que, pertenecieran o no a alguna organización, empezaban a sentirse en el centro de un ambiente de tensión social en el que el clamor por la justicia social, en contra de la desigualdad y la lucha por el reconocimiento de los derechos de los trabajadores, así como la abrumadora pobreza de los campesinos reclamaba una reflexión que tendría que ir más allá de la dualidad contenida en el grito ¡Cristianismo sí, Comunismo no!

6 Meinvielle, Julio. La cosmovisión de Teilhard de Chardin. Estudio crítico. Buenos Aires, 1962, p. 82. 
Cabe destacar que la interpretación de las lecturas o el sentido de las acciones, obviamente, no era igual para todos los jóvenes de la Corporación. La ambigüedad se filtraba en los valores y no bastaba con señalar problemas acuciantes como el de la pobreza o la injusticia social para vaciar el contenido implícito en ese grito desesperado de la política excluyente que llevó a muchos hacia una acción caritativa desprovista de esperanza.

Propuestas de acercamiento como las de la Teología de la Liberación llevan a que las vivencias sean distintas y los escenarios se comprendan desde otra perspectiva.

Aquí, en gran medida, la ruptura tiene lugar cuando los militantes religiosos van quedando inmersos en un proceso social: salen de su pequeño entorno doctrinario, enfrentan aspectos sociales que les aleja sin misericordia de sus ideales devotos y ordenados con los que podrían contribuir a una mejor sociedad. Si bien es cierto que los jóvenes participantes en las organizaciones católicas en México habían desempeñado sus tareas de caridad en favor de lo que consideraban su contribución a la justicia social, también es cierto que su campo de acción estaba regulado por las directrices de la jerarquía católica, al igual que sus tareas y sus posibilidades de vinculación social. Esto era una forma de operación no solamente en los años sesenta, sino desde principios de siglo XX, cuando encontramos diversas organizaciones juveniles y de estudiantes, activas en diferentes escenarios y niveles, todas aquellas secretas, discretas u oficiales, vinculadas a la Acción Católica.

3. Esta experiencia de acción caritativa de CEM y UFEC pasa, pese a todo, por distintos niveles de politicidad. Como laicos, esto puede resultarnos obvio, pero para los católicos practicantes era firme la convicción de que no podían hacer política. 
Sus acciones de ayuda a los desamparados no están recubiertas, bajo ningún motivo, por intencionalidades políticas. El mundo temporal tiene estrecha relación con la moral cristiana. Los acontecimientos políticos y sociales, que encarnan el conflicto social, muestran las debilidades humanas que se superan con el sufrimiento.

En ese discurso hay, evidentemente, una imposibilidad de relacionar al mundo real, el mundo conflictivo de la Guerra Fría, por ejemplo, con el mundo de la lucha por la defensa de las libertades políticas, con el reconocimiento de los derechos civiles: se tiene conocimiento de todas las movilizaciones de los años sesenta en México y en otros lugares del mundo, pero se observan, generalmente, con distancia.

Esta posición no es homogénea: al interior de la propia Iglesia hay sectores que orientan sus empeños a vincularse socialmente, a hacer política - política. Remontando en contra de las orientaciones especificadas en las cartas pastorales. Así podemos entender la participación de grupos católicos en actividades políticas, sosteniendo una postura crítica, situándose al lado de aquellos que enarbolaban distintas banderas en lucha por la justicia social.

Sabemos que las convicciones pasan muchas veces por el tamiz del fervor. En el caso de los grupos católicos, grupos con organización jerárquica, el apasionamiento y la idolatría tiende a oscurecer la razón e inhibe la posibilidad de comprender que en ciertas decisiones y acciones existen intereses no enunciados: a veces en favor de los grupos en el poder, como suele suceder ${ }^{7}$;

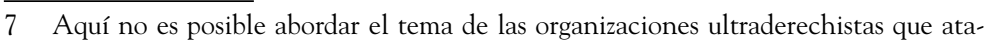
caron a estudiantes del ITESO, en Guadalajara, Jalisco o aquellos que actuaron de manera extremadamente violenta en la Universidad Nacional, en los años sesenta. Al respecto, véase González, Fernando M., Algunos grupos radicales de izquierda y de derecha con influencia católica en México (1965-1975), Revista Historia y Grafía, núm. 29, 2007. 
otras veces, ese acto de caridad se torna un acto de justicia social, en favor de las causas sociales, en favor de los más necesitados.

Uno de los antecedentes más relevantes a este respecto es la experiencia de los sacerdotes obreros en Francia, en años posteriores al fin de la Segunda Guerra Mundial. Ellos decidieron involucrarse por completo entre las comunidades que atendían, con su decisión -oponiéndose valientemente a la condena pastoral- marcaron una pauta de acción que, si bien no era nueva ${ }^{8}$, sí renovó las formas del pensamiento y la acción religiosa.

Cabe destacar que estos sacerdotes obreros eran de la orden de los jesuitas; poco después, con fines de estudio y difusión de la doctrina social católica, surgió L'Action Populaire, también conducida por jesuitas. Despuntaron también los padres dominicos con el grupo Economie et Humanisme, que "quieren construir nuevas estructuras que sirvan de base a una economía orientada no al beneficio, sino a la satisfacción de las necesidades humanas". También en Francia, como parte de la corriente del Movimiento Social Cristiano, tuvieron eco las llamadas Semanas Sociales, uno de cuyos principios era el de la vocación social de los católicos, en un contexto religioso. Las publicaciones y la influencia proveniente de varias instituciones universitarias, así como la labor para la formación de dirigentes en los llamados

8 Las formas de relación entre religiosos y seglares pasaron por un proceso de separación necesario para fortalecer la institucionalidad del clero, para "evitar" la acción política que a lo largo de los años veinte y treinta del siglo XX había complicado las relaciones Iglesia-Estado. Esto significa que las excepciones pudieron darse en dos sentidos: aquellos sacerdotes o grupos religiosos que continuaron actuando, abierta, discreta o secretamente, y en diferentes niveles para justificar las formas políticas gubernamentales. Por otro lado, aquellos sacerdotes, grupos y organizaciones que, sin separarse de los lineamientos religiosos y destacando la relevancia de los actos caritativos y de justicia social, fueron conformando redes vigilantes que acompañaron distintas movilizaciones sociales opositoras al régimen.

9 De Ertze Garamendi, Ramón, El movimiento social cristiano en Europa, Revista Corporación, México, número 3, julio de 1950, p. 19. 
Secretariados Sociales, influyeron en la formación de organizaciones profesionales dirigidas por laicos.

Las características propias de la relación entre el clero y el gobierno en nuestro país marcaron ritmos muy diferentes en cuanto a la actuación del clero progresista: es decir, mientras la actividad de los sacerdotes obreros fue una experiencia recuperada por católicos en Brasil y Chile, lo que probablemente repercutió en el posterior desarrollo de la llamada Teología de la Liberación en Brasil, no era factible en México, en parte por la propia historia de las relaciones Estado-Iglesia: A fines de los años cuarenta continuaba vigente el pacto de convivencia, las relaciones de cordialidad política que no podían quebrantarse.

La Corporación y UFEC tenían, desde sus primeras Asambleas, una fuerte crítica a "las fuerzas que se lanzan al asalto de la cultura occidental", es decir, prefiguraban en la defensa y fortalecimiento del tradicionalismo como la vía para preservar la fe y cultura católica; ello se conseguiría a partir de la "formación de una conciencia universitaria vigorosamente católica"10.

Estas organizaciones no fueron las únicas, son señaladas a manera de ejemplo sin soslayar en las diversas actividades que desde diferentes vertientes iniciaron y sostuvieron algunos católicos en el llamado proceso de liberación popular en México a lo largo de los años sesenta, y que contribuyeron a otra forma de pensar y actuar con justicia social, lejos, muy lejos ya de solo comprometerse con la acción caritativa.

10 Exposición introductoria R. P. Asistente Eclesiástico Nacional, Dr. Dn. David Mayagoitia S. J., Primera Semana de Estudios, Revista Corporación, México, número 4, septiembre-octubre, 1950, p. 14. 
4. Mientras en Brasil y Chile la influencia de los sacerdotes obreros se había dado rápidamente, propiciando reflexiones que desembocaron en la Teología del Desarrollo (1955-1960) y, posteriormente hacia el llamado "cristianismo liberacionista", con sus propuestas de cambio social. En México se pasó (en los años cuarenta), por un proceso de apaciguamiento en las relaciones Iglesia-Estado e incluso hubo grupos que endurecieron sus posturas conservadoras. Cabe señalar que, en los países sudamericanos señalados continuaba latente la resistencia de grupos religiosos que apostaban por la liberación social. Este es el contexto en el cual en México, a fines de los años sesenta, hubo indicios de cambios en la forma de relación entre Iglesia y laicos.

En los documentos de la Corporación de Estudiantes Mexicanos correspondientes a las reuniones celebradas en los años sesenta se observa, por ejemplo, un lento tránsito de rigidez, de estricto apego a las pastorales y encíclicas, hacia una apertura e inserción en discusiones con tendencias libertarias que fueron dándose a lo largo de los años sesenta y, particularmente, entre los meses de junio a septiembre de 1968 .

Las notas de las jóvenes de la Unión Femenina de Estudiantes Católicas dan cuenta de la transformación de su pensamiento, tal vez un proceso de conciencia social en donde, sin detenerse a pensar en las contingencias de lo señalado como el deber religioso, les condujo a otros mares de reflexión. La movilización estudiantil de 1968, misma que experimentaron y siguieron -desde sus escuelas y facultades- paso a paso, fueron analizadas en cada una de las reuniones.

En septiembre de 1968, los jóvenes integrantes de la Corporación y de UFEC, en su documento Escrutando los signos actuales, hacen un pormenorizado relato del movimiento estudiantil indicando: "A partir del informe, los estudiantes comprometidos en 
el movimiento ven menos salidas, sienten que no les queda sino el diálogo o la violencia abierta" ${ }^{11}$.

Tras la violencia desatada en contra de los jóvenes en octubre de 1968, las reflexiones de los corporacionistas se orientaban a hacer un llamado a Obispos, sacerdotes y laicos a reflexionar:

.... fundamentados en información objetiva y en la experiencia personal sobre el conflicto, para discernir sus obligaciones y asumir el compromiso personal y de grupo. No debemos abandonar a nadie, [caridad cristiana] porque lleve alguna etiqueta cuyo contenido efectivo podemos diferir. Debemos respetar prácticamente la libertad de opciones temporales y posiciones ideológicas ${ }^{12}$.

Estos elementos se debatieron intensamente durante la reunión de 1969, cuando la CEM, el grupo del Distrito Federal, pasaba por una de sus peores crisis pues el desánimo y la desorganización habían llegado a tal punto, que muchos de los activos participantes empezaron a declinar en su participación, actuar sin coordinación o, de plano, desertar para incorporarse a otras organizaciones. Esta crisis había iniciado a mostrarse ya desde el Seminario efectuado en Valle de Bravo, cuando varios cuestionaron su propia vida y, "como consecuencia, nos redefinimos como grupo de apostolado en la Universidad".

La visión derrotista se asentaba: "no tuvimos, concluían, la constancia y perseverancia requeridos para un grupo apostólico".

Tiempo después empezaron a circular en las reuniones de la UFEC textos de reflexión orientadas a la Teología de la Liberación en donde los señalamientos sobre lo "inadmisible de la injusticia estructural en el mundo en que vivimos, consolidada y violentamente defendida, sea un dato irreductible o una

11 ADM, UIA, CEM, Escrutando los signos actuales, f.3.

12 Loc cit, f. 6. 
providencia normativa de Dios. Afirmar esto sería, sin más, una blasfemia", señala José María Díaz Alegría, en su texto "Realización inmanente de la conversión cristiana”, documento que circuló entre las integrantes de la UFEC y que, no es cosa menor, dadas las circunstancias de crisis por las que atravesaba la CEM. La crítica valiente sobre la imposibilidad a la que están sujetos los cristianos, atados a una práctica pietista, ajena a la problemática social, que les orilla a actuar únicamente desde la caridad, olvidando los preceptos de justicia social, hace señalamientos como el que sigue:

Sería puro fariseísmo miope ver violencia en los "Guerrilleros", por ejemplo, y no verla en regímenes pesadamente opresivos. Porque sólo no hay violencia donde se realiza, con verdad, un orden social en la justicia y en la auténtica libertad. Es decir, en un orden de amor y fraternidad, de reconocimiento de la persona del prójimo, de todo hombre, de cualquier hombre ${ }^{13}$.

Afirmar que documentos como el referido tuvieron gran impacto para todas las jóvenes de la UFEC y para todos los corporacionistas, sería un exceso. Baste señalar esto como una muestra, situándolo en un contexto en el que muchos de la población joven de la Corporación de Estudiantes Mexicanos habían transitado ya hacia los Comités de Lucha que en los primeros meses de 1969 habían empezado a operar en demanda de la liberación de los compañeros detenidos durante el movimiento de octubre de 1968. Otros, optarían por posiciones más radicales, militantes en organizaciones cuyo principio era el de la acción armada. Muchos de ellos coincidieron, tiempo después, en organizaciones políticas, militantes, a la defensa de los derechos humanos y por la justicia social.

13 ADM, UIA, "Realización inmanente de la conversión cristiana", Díez Alegría., José María Documento 1, CEM/UNAM, México, D. F., noviembre 13 de 1969. 


\section{Fuentes consultadas}

Archivo David Mayagoitia, Universidad Iberoamericana

Aspe Armella, Ma. Luisa. La formación social y política de los mexicanos, México, Departamento de Historia/ Universidad Iberoamericana/ Instituto Mexicanos de Doctrina Social Cristiana, 2008.

Contreras, Gabriela. Los grupos católicos en la Universidad Autónoma de México, México, Universidad Autónoma Metropolitana, Colección Breviarios, 2002.

González M. Fernando. Algunos grupos radicales de izquierda y de derecha con influencia católica en México (19651975), Revista Historia y Grafía, núm. 29, 2007

Meinvielle, Julio. La cosmovisión de Teilhard de Chardin. Estudio crítico. Buenos Aires, 1962.

Revista Corporación. 